\title{
Effective Teaching in the Multicultural Business
}

\section{Classroom}

\author{
Peter R. Woods \\ Peter J. Jordan \\ Rebecca Loudoun \\ Ashlea C. Troth \\ Don Kerr \\ Griffith Business School \\ Griffith University
}

Please direct all correspondence associated with this manuscript to Rebecca Loudoun,

Griffith Business School, Griffith University, Nathan, Qld., 4111, AUSTRALIA Email R.Loudoun@Griffith.edu.au

$$
\begin{aligned}
& \mathrm{Ph}+61(7) 37357743 \\
& \text { Fax }+61(7) 37357177
\end{aligned}
$$

Acknowledgment - This research was conducted using funding from a teaching grant from the Griffith Business School, Griffith University. 


\section{Executive Summary}

With increasing numbers of international students attending university each year, the quality of teaching international students in institutions will become a factor in determining the reputation of universities. It is important that universities develop strategies to ensure that international students receive the best education possible. This article examines learning barriers that arise for international in the university sector and proposes strategies to overcome these barriers from the perspective of teachers and students. Two studies are outlined in this article culminating in the development of a training program aimed at enhancing the effectiveness of teaching a university business course in the multicultural classroom.

Initially, data were collected from focus groups comprising international students and experienced teachers. Using responses from these focus groups a survey was then administered to experienced teachers who work with international students. Major issues identified in these studies that have the potential for reducing teaching and learning quality outcomes center on language problems, gaining effective participation of international students in discussion based activities and the integration of local and international students in project groups.

Drawing on these data and theoretical models of teacher competencies (Ellington, 1999), principles of adult learning (Kolb, 1984), we propose a training program aimed at improving the skills of teachers in the multicultural classroom. The training program, outlined in the paper covers four broad areas: recognition of different teaching models; communication; improving participation and assessment strategies. 
Effective Teaching in the Multicultural Business Classroom

\author{
Peter R. Woods \\ Peter J. Jordan \\ Rebecca Loudoun \\ Ashlea C. Troth \\ Don Kerr
}

\begin{abstract}
Universities continue to attract growing numbers of international students, so addressing how teachers deal with cultural diversity in the classroom has become increasingly important. This paper outlines the development of a program aimed at enhancing the effectiveness of teaching a university business course in the multicultural classroom. Initially, data were collected from focus groups comprising international students and experienced teachers. Following these focus groups, the problems experienced by teachers working with international students in business tutorials were further explored by collecting survey data from experienced teachers. These data were then used to develop a training program with the aim of improving the skills of teachers in the multicultural classroom. The training program focused on four broad areas: recognition of different teaching models; communication; improving participation and assessment strategies.
\end{abstract}

Key Words - International Students, Teaching Strategies, Training

Peter R. Woods B.A. (Qld), BSocWk (Hons) (Qld) is a lecturer in the Department of Management Griffith University.

Peter J. Jordan B.A. (Hons) (Griffith), PhD (Qld) is an Associate Professor in the Department of Management, Griffith University.

Rebecca Loudoun B.A. (Qld), BCom (Hons) (Griffith), $\mathrm{PhD}$ (Qld) is a lecturer in the Department of Industrial Relations, Griffith University.

Ashlea C. Troth B.A. (Hons), PhD (Qld) is a lecturer in the Department of Management Griffith University.

Don Kerr QCA, BSc, PhD (Griffith) is Deputy Head of the Department of Management, Griffith University.

Please direct all correspondence associated with this manuscript to Rebecca Loudoun, Griffith Business School, Griffith University, Nathan, Qld, 4111, AUSTRALIA. Email R.Loudoun@Griffith.edu.au

Acknowledgment - This research was conducted using funding from a teaching grant from the Griffith Business School, Griffith University. 


\section{INTRODUCTION}

Effectively dealing with cultural diversity within the classrooms has become an area of increasing interest and importance for academics as universities continue to attract growing numbers of international students. Recent research examining different approaches to dealing with diversity in teaching (Ofori-Dankwa \& Lane, 2000) stresses the importance of flexibility and 'practicing what we teach' in dealing with cultural diversity (Campbell, 2000), the importance of self esteem for international students (Watson, 1999) and calls for academics to rethink the way they teach in the multicultural classroom (Witte, Sequeira \& Fonteyne, 2003; Northedge, 2003). Clearly, the learning experiences of international students and the difficulties experienced by teaching staff in the multicultural classroom have created challenges for University staff in effectively teaching across cultures (Smith, Miller \& Crassani, 1998).

In this paper, we investigate the learning barriers that arise for international students in the University classroom based on information provided by international students and their teachers. Drawing on theoretical models of teacher competencies (Ellington, 1999), principles of adult learning (Kolb, 1984), and data collected in a survey and focus groups, we propose five strategies to increase participation and understanding of international students and improve the interaction amongst international and domestic students. Finally, a program to improve teacher competencies in the multicultural classroom through a training workshop is outlined. Implications for the education of culturally diverse students in a university setting are also discussed. 


\section{CHALLENGES OF A CULTURALLY DIVERSE CLASSROOM}

The challenges of working in a multicultural classroom have been well documented in the literature. For instance, Northedge (2003) argues that traditional approaches to teaching such as knowledge based or student centred approaches are no longer sufficient for culturally diverse classrooms. He contends that only supported participation can enable students from diverse backgrounds to fully engage with the required knowledge. Ofori-Dankwa and Lane (2000) argue that there are four approaches to dealing with diversity: neutrality that ignores differences and similarities between individuals; similarity that ignores differences and stresses similarities; diversity that ignores similarities and stresses differences; and finally, diversimilarity that acknowledges both similarities and differences. Ofori-Dankwa and Lane (2000) argue that the diversimilarity approach reflects real world complexities whereas the other approaches generally overstate or understate the real situation in classrooms. At a micro level, Watson (1999) has identified the impact of 'loss of face' in teaching in a culturally diverse classroom. She suggests several techniques to ensure that student's self esteem is not degraded due to differences in expectations and attitudes in the classroom.

A number of research projects have also identified the challenges for teachers who work in the multicultural classroom. First, students from non-English speaking backgrounds have been recognised as participating poorly in discussion based tutorials (Flowerdew, 1998). Discussion-based tutorials are classes of one to two hours duration where students discuss lecture topics, engage in experiential activities, analyse case studies and engage in question and answer dialogues with academic teaching staff known as 'tutors' (Kerr, Troth \& Pickering, 2003). The reasons for this lack of participation have been identified as fear of losing face (Bond, 1996), differing 
expectations on the need for participation (Ledwith \& Seymour, 2001) and language and communication difficulties (Desiraju \& Gopinath, 2001). Second, teachers face the challenge of fairly marking written assessment from students whose first language is not English and whose work is frequently characterised by grammatical errors (Mohan, 1992). Third, teachers must deal with the difficulty that international students face in relating to or applying concepts that are strongly framed within the confines of the local national context (Hellmundt, Rifkin, \& Fox, 1998). Finally, teachers find it difficult to encourage critical thinking and analysis amongst students whose previous educational experiences have neglected or discouraged this approach to learning (Smith et al., 1998; Witte et al., 2003).

\section{STRATEGIES FOR TEACHING CULTURALLY DIVERSE STUDENTS}

Teachers who have experience in a multicultural classroom have advocated a broad range of techniques to overcome issues that restrict learning. For instance, George (1994) recommended and tested co-operative learning techniques and concepts that help students to learn together in the multicultural university classroom. Co-operative learning involves groups of about four members working together on a task where members are individually accountable for their part of an outcome that requires a co-operative effort for successful completion (Johnson \& Johnson, 2000). Another specific strategy is the 'think-pair-share' technique developed by Lyman (cited in George, 1994) where, after listening to a question about a reading, students were given time to frame an answer and pair with a learning partner for conferring, before being called on randomly to share their collective answer with the class. A 'drill and review' strategy has also been successfully tested in multicultural university classrooms (George, 1994). This strategy divides the class into dyads with one student recalling what was taught (driller) and one student listening and responding to 
the review (reviewer). Roles would be reversed for other exercises, and this dyad would remain together throughout the course.

Another co-operative learning strategy used with multicultural classes is the peer tutoring method (Slavin, 1990). This method usually involves a more permanent tutoring relationship between a higher performing or more advanced student and a student peer. The method has been shown to improve the academic performance, attitude and motivation of the student tutor and the student peer through the processes of recall and explanation (Slavin, 1990).

Experiential learning theory - a process through which knowledge emerges by transforming experience (Kolb, 1984) - also helps to inform the development of teaching competencies for teachers in the multicultural classroom (Murray, 1993). Helping students to identify and share their experience related to the concepts being discussed in class taps into and opens up the diversity of experiences and perspectives available in the multicultural classroom (Ottewill \& Laughton, 2001).

Adler (2002, p.146) suggests that multicultural groups "have the potential to invent more options and create more solutions than do single-culture teams." Sharing of experiences and perspectives, however, are more likely to occur when the group is able to recognise, understand and respect cultural differences, where the value of diversity is recognised and encouraged by the facilitator and members, and where the facilitator is adept at providing positive feedback on process and output to the group (Adler, 2002). Using experience in the cycle of conceptualising, acting, experiencing and reflecting can only occur when the variety of cultural experiences present in the classroom are validated and shared. An international student may not make the connection between their experience and a relevant new concept if the contextual framework and illustrations used seem exclusively linked to the host culture 
(Mainemelis, Boyatzis, \& Kolb, 2002). Hence the teacher can facilitate the process by using a variety of international illustrations and validating relevant and diverse cultural experiences when they are shared.

\section{Group Formation Strategies}

Two of the important factors in forming effective groups with culturally diverse individuals are the explicit establishment of group norms and group roles (Johnson \& Johnson, 1997; Ottewill \& Laughton, 2001). These factors are particularly important in conducting and planning the first meeting of any student group. Groups norms are the group's common beliefs regarding appropriate behavior, attitudes and perceptions for members ( Johnson \& Johnson, 1997). Although norms are commonly regarded as being culturally bound (Gudykunst, Ting-Toomey, \& Chua, 1988), it is possible to be deliberate in their prescription within a new group. Group theorists (Johnson \& Johnson, 1997) and intercultural communication theorists (Gudykunst et al., 1988) define norms differently. The negotiable aspect of norms in group theory (Johnson \& Johnson, 1997) is interpreted by (Gudykunst et al., 1988) as equating with the meaning of rules in intercultural communication theories. Norms (as defined by group theorists) need to be made explicit in the first tutorial, often through a process of discussing behavior and attitudes openly, so that an alignment of expectations amongst students from different cultural backgrounds is possible. Rules in groups are co-determined principles (Gudykunst et al., 1988) and are often established in tutorials through a collective listing of "what will make the tutorial successful' and 'what will make the tutorial unsuccessful' in the first tutorial meeting.

Another important issue for enhancing learning in the multicultural classroom is the clear definitions of roles. A role is the set of expectations that define the appropriate behaviour of someone occupying a position towards other related 
positions (Johnson \& Johnson, 1997). In intercultural terms, the dimensions of roles could be seen in terms of how 'personal' the relationship is, how 'formal' participants' behaviour should be, the degree of hierarchy present in the relationship, and the how far one is allowed to deviate from the 'ideal' role enactment" (Gudykunst et al., 1988, p.71,72). These dimensions have significance for the teacher who is attempting to build a teaching relationship with students, and again the teacher must make explicit how they see their teaching role and what role they expect the students to play in the class. This concept is especially relevant to teachers from cultural backgrounds that differ from the majority of the class, particularly with regard to how 'personal' relationships can be formed, the formal use of titles, allowance for interjections, methods of addressing the teacher and fellow students and the teaching style of the teacher.

The challenges of forming and developing students as a group must also take into account the particular processes that characterize diverse group management. Table 1 presents an outline of the processes involved in building a diverse task oriented group, which has relevance to teaching situations where task based activities or teams are part of the learning process (Adler, 2002). Of particular importance is the recognition that diversity within a group makes trust building and developing consensus more difficult. The recognition, acceptance and understanding of differences as well as the ability to recognize and develop similarities are important competencies in managing group diversity.

\section{Insert table 1 about here}

In summary, research to date has shown that some students from culturally diverse backgrounds have problems in tutorials related to participation, marking, spoken and written communication, critical analysis, and application of concepts to 
their own contexts. Existing strategies to overcome these problems include cooperative learning (Johnson \& Johnson, 2000), 'think-pair-share' and 'drill and review' (George, 1994) and peer tutoring (Slavin, 1990). Beyond these techniques, enhancing the skills of teachers to facilitate diverse groups can also help to minimize learning barriers for international students.

This research provides valuable insight into the learning experience of international students but further research is need to assess the applicability of the findings for a wider range of students in different settings. Further research is also needed about techniques that teachers can use to facilitate diverse groups.

With this research in mind the present study sought to examine issues and problems that arise for international students in the university business classroom with a view to designing a training program aimed at improving teaching in the multicultural classroom. Data were collected using focus groups and surveys from teachers and international students.

\section{STUDY 1}

In Study 1 we convened two focus groups. The purpose of the focus groups was to gather issues that arose in culturally diverse classrooms from the perspective of both teachers and their international students. This study was intended to confirm the findings of the extant literature and to develop our practical understanding of issues that emerge in a multicultural classroom.

The first focus group gathered information from international students about their experiences of being taught in a western university system. The second focus group gathered data from experienced teachers of international students. The research questions for this study were: 
1. What barriers to learning do international students experience in tutorial classes?

2. What difficulties do teachers experience in teaching international students?

3. How can the learning barriers experienced by international students be overcome by appropriate teaching strategies?

\section{Method}

The first focus group comprised six international students who were studying postgraduate programs and had wide experience in international education. All participants had a minimum of 3 years experience as international undergraduate students. Each participant was from a different country and they were, India, China, Vietnam, United Arab Emirates, Malaysia and Zimbabwe. The participants ranged in age from 21 to 30 years: two participants were female. The focus group session lasted for approximately an hour.

The second focus group involved five experienced business teachers who had worked teaching international undergraduate and postgraduate students. The age of participants ranged from 26 to 44 years: two participants were males. The participants of this focus group had a minimum teaching experience of three years. This focus group session lasted for approximately an hour.

\section{Procedure}

The questions used in the focus groups are listed in Tables 2 (Student Focus Group) and 3 (Teacher Focus Group). The focus group responses were recorded and transcribed. To collect these data, a modified version of the nominal group technique (Delbecq, Van de Ven, \& Gustafson, 1975) was used. Individuals were asked to 
generate ideas independently before bringing them back to the group. These ideas were compared and categorized to distil key themes. Participants were then able to vote for the three most significant responses to the focus group questions, with 3 points for the most significant response, 2 points for the second most significant and 1 point for the third most significant. Responses that scored four points or above are recorded in Tables 2 and 3.

\section{Results}

The results of the international students' focus groups are outlined in Table 2. The vote scores were derived from the nominal group method as previously described and are based on a voting pattern that allows the researcher to gather data on strength of importance of the topics. Based on these results, students strongly identified the need for teachers to encourage participation. This was considered a prime concern. In response to the focus group question on what international students need most from their teachers, the participants' major response was that students "need to be encouraged to interact - facilitating a more encouraging environment" (Table 2, Q.1, i). Language difficulties were also prominent in the students' discussion.

\section{Insert table 2 about here}

The importance of the issues outlined in Table 2 are best illustrated by discussions during the focus groups. For instance, Participant 1 noted in relation to the language difficulties experienced by international students that "some people have a problem with communication in terms of the teacher's accent". Similarly, Participant 4 suggested that "teachers need to speak more slowly and not ignore us when they know we don't understand". Similarly focus group discussions also provided useful insights into international students' perceptions. For instance, Participant 2 noted that "at first answering questions seemed like a waste of time as 
we were waiting for the teacher to give us the answers, but later on I realized that one can actually learn by interacting with other students about the class topics".

Turning to the results of the teachers' focus groups (Table 3) it is clear from the data that the teachers were much more aligned in their opinions of issues of importance. Again, the data reported in Table 3 were derived using a modified version of the nominal group method. The data clearly indicate that teachers see language as being of prime importance in determining the outcomes of learning for students. Language competency emerged as the issue of most concern in response to two questions in the focus group. Encouraging participation was also seen as important.

\section{Insert table 3 about here}

Again the data collected using the nominal group technique was reflected in some of the statements recorded from the teachers. For instance in terms of language, Participant 7 noted that "English language skills not up to standard for many students - how does a tutor know whether the point has been understood?” In a similar vein, Participant 11 noted that "some international students are ostracized by the local students with an assumption that poor English skills mean low intelligence." Looking at other major issue, Participant 8 noted that participation was a key ingredient in student success and noted "some international students tend to come to lectures for a while then drop out when they find they cannot benefit from them due to problems with language and unfamiliarity with a participative teaching style”. Participant 9 commented that "many international students lack the confidence to participate and there seems to be cultural issues behind this passivity". Participants suggested that a major strategy to overcome this is to "establish group norms at a session in the beginning of the semester and this should include reference to the diversity of cultures 
within the class" (Table 3, Q.6, i).

\section{STUDY 2}

While the focus groups study provided detailed insight into the issues that faced both international students and the teachers of those international students, the sample size was small and thus the generalisabiliy of the findings was limited. In an attempt to address this shortcoming a survey exploring the same topic was administered to experienced teachers. The survey used open ended questions in an effort to draw participants into the areas of interest as identified in the focus groups while still leaving participants free to bring up information that may not have already been mentioned. The open ended questions asked respondents to firstly list three main difficulties they encounter in teaching international students and then to list three main strategies they used for improving the teaching experience.

Participants for the study were drawn from two universities in response to advertisements for experienced teachers to nominate for a training program to improve teaching of international students. Fifty-two teachers volunteered for the training program and completed surveys prior to the training. Forty-seven of these teachers provided usable responses. Respondents had a broad range of experience in teaching with all respondents having a minimum of 3 years experience of teaching. Respondents were an average age of 39.7 years and 22 of the participants were female.

\section{Results}

The teacher's responses to open-ended questions were collated using thematic content analysis (Strauss, 1987) and the major responses are listed in tables 4 and 5. Results (Table 4) indicate that a majority of participants saw language as a problem in 
teaching. This is also confirmed in the comments provided. For instance, in response to identifying teaching difficulties, one respondent noted problems with "poor English language skills in written form contributing to plagiarism". Another noted that in his experience there was a "difficulty in getting international students to understand complex situations due to language barriers". This may also be linked to another concern identified, namely the difficulty in getting international students to participate in class discussions. Again this was reflected in comments gained in the surveys which included teacher expressing "difficulty in achieving participation from the majority of students on a regular basis". A significant number of the respondents just put down a single word "participation".

\section{Insert Table 4 about here}

Teachers seemed to cope with the challenges of tutoring international students through providing individual attention in consultation hours, via email contact, and discussion with students after the class or even during class (Table 5). A number of teachers identified careful listening and making a special attempt to understand and empathize with international students as being an important strategy.

\section{Insert Table 5 about here}

\section{DISCUSSION}

After an examination of the major responses of the focus groups and survey it is clear that the major issues raised involved the use of language in tutorials. Both students and teachers listed language problems as being their major concern in tutorials, and both groups provided simple strategies to address this problem. Language issues emerged as a major theme as it was mentioned in six different categories used to elicit the focus group responses (see Tables 2 and 3). This issue also emerged frequently in the open-ended questionnaire as an issue for teachers of 
international students (see Table 5). Clearly, this supports previous research (Desiraju \& Gopinath, 2001; Mohan, 1992).

Because language difficulties emerged as such an issue within the two focus groups and in the survey we examined the data to distill more succinctly the issues that facilitated effective language use and those that hindered effective communication. The details of the combined student and teacher focus groups response are listed in Table 6.

\section{Insert Table 6 about here}

Another major theme to emerge from both the focus group and the survey was the issue of participation. Problems and suggested solutions regarding group participation also arose in five focus group responses and 27 survey responses, again indicating that this is a major issue of concern for both staff and students. This confirms the broad thrust of the extant literature in this area which has identified participation as an issue (Ledwith \& Seymour, 2001; Bond, 1996).

The next stage of the research involved devising discussion and facilitation strategies to address these problems identified with student participation in the multicultural classroom. Five strategies were devised using data collected from the focus groups and the survey, existing research (particularly Adler's (2002) comprehensive framework for managing diversity in teams) and, the combined experiences of the authors. The strategies are Break Up and Report Back; Think, Write, Share; Question Clarity; Peer Explanation; and, Student Examples. These strategies are explained in the following sections and linked to the research data and literature from which they were derived.

'Think, Write, Share' 
This method is similar to the 'think-pair-share' method proposed by George, (1994). However the 'think-write-share' strategy as suggested here is intended to help students who require more time and help to frame their responses in the discussion language. Using this technique the class is asked a question and then given a time limit in which to write their answers in point form. Students are then asked to share their answers with the class, and in most cases, students with weaker English language skills should be asked first. This approach is intended to help the 'ditto' type responses as answer points are progressively exhausted when students provide their answers in turn.

This strategy was derived from the focus group sessions where the participants identified the need for international students to have time develop their ideas in English due to language competence problems (Table 2, Q.1 i, Q.2 i). One participant in Study 2 suggested that teachers must give international students "an opportunity to write their feedback for the class as they may not be able to SAY it".

\section{'Question clarity'}

In Study 2 participants identified the need for international students to be clear about the concepts they were learning which many not have a direct translation from English to their own language (Table 4, Issue a). In the student focus group, participants emphasised that greater clarity in the presentation of topic headlines and discussion questions was needed in class. From these findings we devised a method of allowing students to undertake concept clarification through the simple act of providing questions visibly through writing the discussion question on the board or by electronic projection. The visual prompt helps to provide an anchor point for the student, which is especially useful when students question themselves about whether they understood the question in the first place as the discussion drifts away from 
answering the question itself. Visual aids have been shown to be helpful in crosscultural communication (Adler, 2002), and need to be deployed in effective teaching in the multicultural classroom.

\section{'Peer Explanation'}

In the teacher focus group, teachers questioned what they could do when they perceived the 'glazed look' of students who did not appear to understand what was being taught (Table 3, Q.1, i). Teachers agreed that simply asking 'do you understand?' or 'any questions?' would rarely yield a satisfying response, particularly when admitting confusion may be seen as a 'loss of face' to some students (Watson, 1999). An effective strategy that can be employed in this situation is to ask who in the class is clear on the point being explained. These 'experts' can then be assigned to small groups of students to help explain the concept. These 'experts', are likely to gain more in the process through the 'peer tutoring' benefits previously described (Slavin, 1990). This strategy applies the principles of the 'peer tutoring method' (Slavin, 1990) within the University classroom in a changeable and concept specific basis.

\section{'Student Examples'}

One of the strengths of having diverse students in class identified during the focus group sessions was the ability of international students to bring different examples from their background into the class (Table 2, Q.4, ii). Participant 18 in Study 2 suggests that international students should be utilized "as a resource for cultural differences and diversity" (Table 5, Issue g). This not only validates the experience of the international student but also enhances the experience of domestic students. In order to help tap into the diversity of experiences within the class, we suggest that students are asked to think of an example from their own experience or 
from their reading that may illustrate the concept being discussed. This helps students to connect tacit knowing and explicit knowledge (Cuncliffe, 2002), an important step in engaging in a reflexive dialogue. Similarly, the recognition of experience helps in the experiential learning process (Kolb, 1984). Students can write points on their example within a time limit, and then the teacher selects a few students to share their ideas with the class based on what they have written. This strategy can be extended to an application of the 'jigsaw method' where all students are recognized as being specialists in particular areas and they then work to help other students understand their area of specialty within the context of a mutual project (Sharan, 1994).

\section{'Break Up and Report Back'}

This simple strategy involves the teacher dividing the class into smaller culturally mixed groups of two, three or four participants. The teacher then assigns a question for each group to address, or ask all groups to address a list of questions. Each group would be given a time limit to complete the task and informed that one person should be appointed as the presenter to the larger group. This provides a less threatening small group environment where the student with weaker language skills can first test out their understanding as well as their responses to the questions asked before speaking to the larger group.

Participants in the student focus group felt that the teacher dividing the class into groups was usually better than self-selection as this helps to form groups with a mix of cultures and languages (Table 2, Q.6 i). The results from Study 2 also emphasised that teachers need to encourage or require mixed cultural groups (Table 5, Issue d). The student focus group also stressed that class participants need to be encouraged to interact as part of facilitating a more encouraging environment (Table 2, Q.2 i). This strategy is a method of encouraging interaction as it is more difficult to 
avoid interaction with other students in a smaller group. This strategy helps to address one of the major teaching difficulties identified in Study 2, that being the confidence of students (Table 4, Issue f). Student confidence can be improved through providing an opportunity to test ideas with a smaller audience before presenting them before the larger audience of the class. The strategy also helps students through the use of group dynamics as suggested by teachers in Study 2 (Table 5, Issue f).

Our analysis of the data collected during the studies outlined was used to develop a training program to enhance teaching experiences in a multicultural classroom. This program is outlined in the next section.

\section{THE TRAINING PROGRAM}

In order to disseminate the findings of our research we developed a training program aimed at experienced university teachers to improve their teaching of international students. The training program was based on theories of adult education and the experiential learning cycle (Kolb, 1984) and research into teaching competencies for university teachers. Ellington (1999) identifies a number of core competencies for teachers in university education including writing student learning outcomes; planning and implementing the instruction process; producing teaching/ learning materials; assessing student performance; and, evaluating the effectiveness of the instruction system. Given the relatively short time we had for the training (one day) the research team decided to focus on the two major competencies that emerged during our data collection that were identified by both students and teachers in the focus groups as making a difference in teaching international students by. These competencies were (1) teaching in the classroom and (2) assessment of the students' 
work. In developing the curriculum for the training day we therefore focused on those issues.

The teacher-training workshop was conducted twice in two University Business Groups with experienced teachers. Fifty-two teachers in total participated. The objectives for the program were to ensure more appropriate teaching and communication approaches when working with international students, to increase the involvement of international students in classroom discussion and activities, to increase cultural awareness and the development of classroom facilitation and management skills (linked to competency 1) and to increase teacher's ability to assess international students more fairly and consistently (linked to competency 2).

The first session of the training program involved icebreakers and information sharing (Smith, 1998). This provided an opportunity for participants to outline the difficulties they experienced in teaching in the multicultural classroom, and strategies they have found effective in addressing those difficulties. In facilitating this session we linked the participant's comments to the findings of data collection phase of this project. This session enabled participants could clarify issues, affirm common concerns and share possible solutions. The findings of the focus groups and preworkshop surveys were used to supplement and illustrate the issues and strategies raised.

The second session was intended to increase cultural sensitivity, cultural empathy and cultural confidence through exploring how the classroom expectations of students from different cultures may differ from the Australian norm (as recommended by Barker, Troth, \& Mak, 2002). This session laid the groundwork for considering participation strategies that could be pursued in the classroom. The workshop participant group was divided into sub-groups based on their knowledge or 
experience of different national education systems or values to discuss different educational models. These groups then reported back to the main group, illustrating to participants how diversity becomes a valuable resource in discussion based instruction. This was further reinforced when a panel of international students presented their own perspectives on teaching, and participants rated this as the most valuable session in the post-workshop evaluation.

The next session and focused on the issues of enhancing participation and engagement and addressing the problems of language, participation and classroom interaction (Competence 1) identified from the data collected. In this session we incorporated interactive exercises where various strategies to improve participation were presented and discussed, including those listed above in the discussion. This process further illustrated experiential learning theory teaching methods (Kolb, 1984).

The final session dealt with the practical issues of marking international student's assignments (Competence 2). Marking issues were addressed in the workshop by training teachers in using the assessment based criteria guidelines provided by the University. Strategies for addressing grammar or spelling problems included asking the student to submit their work for assessment after having the work checked by a person with more experience in academic writing, having only part of the assessment criteria related to grammar and spelling or failing the item because the marker could not understand what was written. A clear policy at the University level would be needed to achieve consistency and fairness.

Feedback from the participants of this training session was positive. Teachers were asked to rate the workshop overall on a 7 point scale from 1 (poor) to 7 (excellent). The average rating was 5.92 with a standard deviation of 0.64 . Participants were also asked, "What they were taking away from the workshop by 
way of learning or personal development". Several responded along the lines that they had, "a clearer idea of how students see things - their background and expectations of roles," and that they were provided with "ways of facilitating student centered learning other than being teacher-centered".

Despite these positive responses there are a number of limitations in the data collections leading up to the training program and in evaluation of the training program that need to be kept in mind when considering the program. First, the numbers involved in the focus groups were small. This may have restricted our ability to accurately discern the broad issues around international student needs. In selecting participants for the two focus groups, however, we note that we focused on selecting participants who had significant knowledge of this topic. Support for the efficacy of our findings from the focus group is found in the fact that the issues that emerged across the two focus groups, also emerged during the survey process.

Second, there may also be issues surrounding the generalisability of our findings as participants were drawn from two universities only with students and teachers who work in the area of business and management related subjects. We do note, however, that the participants in both studies had studied and worked across a number of institutions. We consider that these participants would have drawn on this experience in providing their responses.

Third, the assessment of the training program requires further investigation. While we have obtained evaluation data from the participants, the true measure of any training program is changes in behaviour (Smith, 1998). Further research is required to establish the effect of the training program on teachers' interactions with international students to establish whether they do indeed assist in improving the effectiveness of teaching in the multicultural classroom. 


\section{CONCLUSION}

With increasing numbers of international students attending university each year, the quality of teaching international students in institutions will become a factor in determining the reputation of universities. It is important that universities develop strategies to ensure that international students receive the best education possible. This article has provided an overview of the major issues associated with teaching international business students in a university environment with the aim of improving teaching and learning quality.

Major issues that have the potential for reducing teaching and learning quality outcomes center on language problems, gaining effective participation of international students in discussion based activities and the integration of local and international students in project groups. The findings affirm and expand on previous research in the area by further developing a number of strategies based on teacher and student suggestions that may prove useful to teachers in improving their effectiveness in teaching international students.

\section{REFERENCES}

Adler, N. (2002). International dimensions of organizational behavior (4th ed.). Cincinnati: South-Western.

Barker, M.C., Troth, A., \& Mak, A. (2002). Transition to a new academic context: Intercultural skills training for international postgraduate students. Paper presented at the 10th Post Compulsory and Education Training Conference, Gold Coast, Australia, December 7-9.

Bond, M. H. (1996). Handbook of Chinese Psychology. Hong Kong: Oxford University Press. 
Campbell, A. (2000). Cultural diversity: Practicing what we preach in higher education. Teaching In Higher Education, 5(3), 373 - 384.

Cuncliffe, A. L. (2002). Reflexive dialogical practice in management learning, Management Learning, 33(1), 35-61.

Delbecq, A., Van De Ven, A., \& Gustafson, D. (1975). Group techniques for program planning: A guide to nominal group technique and delphi processes. Glenview ILL: Scott Foresman.

Desiraju, R., \& Gopinath, C. (2001). Encouraging participation in case discussions: A comparison of the MCIA and the Harvard case methods. Journal of Management Education, 25(4), 394-408.

Ellington, H. (1999). Reconciling conflicting demands in the training of HE teachers - the experience at The Robert Gordon University. Education and Training, 41(1), 27-32.

Flowerdew, L. (1998). A cultural perspective on group work. ELT Journal, 52(4), 323-329.

George, P. G. (1994). The effectiveness of co-operative learning strategies in multicultural university classrooms. Journal on Excellence in College Teaching, $5(1), 21-31$.

Gudykunst, W.B., Ting-Toomey, S., \& Chua, E (1988). Culture and interpersonal communication. Newbury Park: Sage.

Hellmundt, S., Rifkin, W., \& Fox, C. (1998). Enhancing intercultural communication among business communication students. Higher Education Research and Development, 17(3), 333-344.

Johnson, D., \& Johnson, F. P. (1997). Joining Together: Group Theory and Group Skills. Boston: Allyn and Bacon. 
Johnson, D., \& Johnson, R. (2000). Cooperative learning, values, and culturally plural classrooms. In: M. Leiester, C. Modgil \& S. Modgil (Eds.), Classroom Issues: Practice, Pedagogy and Curriculum. London: Falmer Press.

Kerr D.V., Troth A., \& Pickering A. (2003). The use of role-playing to help students understand information systems case studies. Journal of Information Systems Education, 14 (2), 167-171

Kolb, D. A. (1984). Experiential learning: Experience as the source of learning and development. Englewood Cliffs: Prentice Hall.

Ledwith, S., \& Seymour, D. (2001) Home and away: Preparing students for multicultural management. International Journal of Human Resource Management, 12(8), 1292-1312.

Mainemelis, C., Boyatzis, R. E., \& Kolb, D. A. (2002). Learning styles and adaptive flexibility. Management Learning, 33(1), 5-33.

Mohan, B. (1992). What are we really testing? In: P. Richard-Amato, M. Snow (Eds.), The Multicultural Classroom. New York: Longman.

Murray, G. (1993) The inner side of experiential learning, In: T. Gochenour (Ed.), Beyond Experience - An Experiential Approach To Cross-Cultural Education (2nd ed.). Yarmouth: World Learning.

Northedge, A. (2003). Rethinking teaching in the context of diversity. Teaching In Higher Education, 8(1), 17 - 32.

Ofori-Dankwa, J., \& Lane, R.W. (2000). Four approaches to cultural diversity: Implications for teaching at institutions of higher education. Teaching In Higher Education, 5(4), 493 - 499. 
Ottewill, R. \& Laughton, D. (2001). East meets West: Using multi-cultural groupwork to develop the cross-cultural capability of tomorrow's international managers, Journal of Teaching in International Business, 12 (1), 1-22.

Sharan, S. (Ed.) (1994). Handbook Of Cooperative Learning Methods. Westport: Greenwood Press.

Slavin, R. E. (1990). Cooperative Learning: Theory, Research and Practice. Boston: Allyn and Bacon.

Smith, A. (1998). Training and Development in Australia 2nd Ed. Sydney: Butterworths.

Smith, S., Miller, J., \& Crassani, B. (1998). Approaches to studying of Australian and overseas university students. Higher Education Research and Development, 17(3), 261-276.

Strauss, A. (1987). Qualitative Analysis For Social Scientists. Cambridge: Cambridge University Press.

Watson, D.I. (1999). 'Loss of face' in Australian classrooms. Teaching In Higher Education, 4(3), 355 - 362.

Witte, A.E., Sequeira, I. \& Fonteyne, C. (2003). Internationalizing the assessment criteria to build cross-cultural competency: American and Chinese educational encounters. Journal of Teaching in International Business, 14 (4), 61-78.

Zikmund, W.G. (1991). Business Research Methods. Orlando, FL: Harcourt, Brace, Jovanovich Inc. 
Table 1

Managing Diversity Based on the Team's Stage of Development

\begin{tabular}{llll}
\hline Stage & Process & $\begin{array}{l}\text { Diversity } \\
\text { Makes the } \\
\text { Process: }\end{array}$ & Process Based On: \\
\hline $\begin{array}{l}\text { Entry: Initial team } \\
\text { formation }\end{array}$ & $\begin{array}{l}\text { Trust building } \\
\text { (developing } \\
\text { cohesion) }\end{array}$ & More difficult & $\begin{array}{l}\text { Using similarities and } \\
\text { understanding } \\
\text { differences }\end{array}$ \\
$\begin{array}{l}\text { Work: Problem } \\
\text { description and } \\
\text { analysis }\end{array}$ & $\begin{array}{l}\text { Ideation (creating } \\
\text { ideas }\end{array}$ & Easier & Using differences \\
$\begin{array}{l}\text { Action: Decision } \\
\text { implementation }\end{array}$ & $\begin{array}{l}\text { Consensus } \\
\text { building (agreeing } \\
\text { and acting) }\end{array}$ & More difficult & $\begin{array}{l}\text { Recognising and } \\
\text { creating similarities }\end{array}$ \\
\hline \begin{tabular}{l} 
Source: Adler, 2002,151 \\
\hline
\end{tabular}
\end{tabular}

Source: Adler, 2002, p.151 
TABLE 2

Student Responses to Listing Importance of Issues using Modified Nominal Group Technique*

\begin{tabular}{|c|c|c|}
\hline Q.1 & $\begin{array}{l}\text { What have you found challenging/difficult about participating in } \\
\text { tutorials/workshops and in interacting with teachers? }\end{array}$ & $\begin{array}{l}\text { Vote } \\
\text { Score }\end{array}$ \\
\hline $\mathrm{i}$ & $\begin{array}{l}\text { Some people have a problem with communication - accent and also cultural } \\
\text { bias in teaching attitudes - participative versus authoritative }\end{array}$ & 7 \\
\hline ii & Some seemed to be inexperienced in teaching & 6 \\
\hline iii & Equipment problems & 4 \\
\hline iv & $\begin{array}{l}\text { Lecture notes should be posted four hours before the lecture itself so that } \\
\text { students who have difficulty with the language could prepare themselves. }\end{array}$ & 4 \\
\hline Q.2. & $\begin{array}{l}\text { What would you say are the needs of international students in } \\
\text { tutorials/workshops and in dealing with teachers? }\end{array}$ & \\
\hline $\mathrm{i}$ & $\begin{array}{l}\text { Participants need to be encouraged to interact - facilitating a more } \\
\text { encouraging environment. }\end{array}$ & 13 \\
\hline ii & $\begin{array}{l}\text { Feedback about choice of career and the subjects they might need to choose } \\
\text { was a need for many students }\end{array}$ & 8 \\
\hline iii & $\begin{array}{l}\text { Different cultures have different past experience ways of conducting exams. } \\
\text { Some students do not have experience with multiple-choice questions. }\end{array}$ & 4 \\
\hline Q.3. & $\begin{array}{l}\text { What would make tutorial/workshop participation and interacting with } \\
\text { teachers more effective for your learning? }\end{array}$ & \\
\hline $\mathrm{i}$ & Teachers should act as a bridge between lecturer and tutor. & 6 \\
\hline ii & Lecturers need to be more friendly & 5 \\
\hline iii & Lecturers need to have respect for students. & 5 \\
\hline iv & Lecturers need to be more accessible & 4 \\
\hline Q.4. & $\begin{array}{l}\text { What do you think are the strengths of having a mix of cultures in the } \\
\text { tutorial/workshop classroom? }\end{array}$ & \\
\hline $\mathrm{i}$ & $\begin{array}{l}\text { Learning to adapt is a vital component of our future work- } \\
\text { E.g. adapt to accents. }\end{array}$ & 10 \\
\hline ii & $\begin{array}{l}\text { Different insights resulted because we learned from other cultures, represented } \\
\text { a wider point of view. }\end{array}$ & 6 \\
\hline Q.5. & $\begin{array}{l}\text { What weaknesses /problems do you see in having mix of cultures in the } \\
\text { tutorial/workshop classroom? }\end{array}$ & \\
\hline $\mathrm{i}$ & Language difficulties resulted & 9 \\
\hline ii & $\begin{array}{l}\text { Some people found the difficulties too challenging and the discussion became } \\
\text { a boring argument along race lines. }\end{array}$ & 7 \\
\hline iii & Inexperience of how to participate in a tutorial by some & 5 \\
\hline Q.6. & $\begin{array}{l}\text { What advice would you give to teachers who want to improve their } \\
\text { effectiveness in teaching international students? }\end{array}$ & \\
\hline $\mathrm{i}$ & $\begin{array}{l}\text { The lecturers need to speak slower, be more casual with less compulsory } \\
\text { activities e.g. assessments etc. }\end{array}$ & 6 \\
\hline ii & $\begin{array}{l}\text { In the beginning of the semester, students should be helped to form groups, } \\
\text { and these groups should be formed with a mix of cultures. }\end{array}$ & 6 \\
\hline iii & Be adept in practice at facilitation of opinions, accepting all points of view. & 4 \\
\hline
\end{tabular}

$* n=6$ Maximum score for a single issue is 18 . Maximum score for a theme is 36 . Answers that scored below 4 points are excluded. 


\section{TABLE 3}

Teacher Responses to Listing Importance of Issues using Modified Nominal Group Technique*

\begin{tabular}{|c|c|c|}
\hline Q.1 & $\begin{array}{l}\text { What have you found challenging/difficult about participating in } \\
\text { tutorials/workshops and in interacting with teachers? }\end{array}$ & $\begin{array}{l}\text { Vote } \\
\text { score }\end{array}$ \\
\hline $\mathrm{i}$ & $\begin{array}{l}\text { English language skills not up to standard for many students - how does a } \\
\text { teacher know whether the point has been understood? }\end{array}$ & 15 \\
\hline ii & Cultural values intervene to impede learning - shyness, for example. & 5 \\
\hline iii & $\begin{array}{l}\text { Some International students tend to come to lectures for a while then drop out } \\
\text { when they find they cannot benefit from them. }\end{array}$ & 4 \\
\hline Q.2. & $\begin{array}{l}\text { What would you say are the needs of international students in } \\
\text { tutorials/workshops and in dealing with teachers? }\end{array}$ & \\
\hline $\mathrm{i}$ & Better English is a key need. & 15 \\
\hline ii & Passivity and lack of confidence in participation. & 4 \\
\hline iii & Encouragement and lack of intimidation/intolerance by local students & 4 \\
\hline Q.3. & $\begin{array}{l}\text { What would make tutorial/workshop participation and interacting with } \\
\text { teachers more effective for your learning? }\end{array}$ & \\
\hline $\mathrm{i}$ & $\begin{array}{l}\text { Teachers should foster inter-cultural participation and experience for } \\
\text { International students as well as locals. }\end{array}$ & 10 \\
\hline ii & There should be extra introductory sessions for International students. & 5 \\
\hline iii & $\begin{array}{l}\text { The "common time" experiment of free access to teachers at a single time } \\
\text { should be expanded throughout the system. }\end{array}$ & 4 \\
\hline iv & $\begin{array}{l}\text { Groups should be chosen to create diversity of cultural experience - a mixed } \\
\text { demographic is preferred. }\end{array}$ & 4 \\
\hline Q4. & $\begin{array}{l}\text { What do you think are the strengths of having a mix of cultures in the } \\
\text { tutorial/workshop classroom? }\end{array}$ & \\
\hline $\mathrm{i}$ & It breaks down communication barriers based on culture. & 8 \\
\hline ii & Cultural exchange increases students' sensitivity and awareness. & 7 \\
\hline iii & Cultural stereotypes tend to be broken down. & 4 \\
\hline iv & $\begin{array}{l}\text { The security blanket that cushions some students is removed - a move beyond } \\
\text { the comfort zone experience which is beneficial. }\end{array}$ & 4 \\
\hline Q5. & $\begin{array}{l}\text { What weaknesses /problems do you see in having mix of cultures in the } \\
\text { tutorial/workshop classroom? }\end{array}$ & \\
\hline $\mathrm{i}$ & Some students become shyer as a result of the experience. & 8 \\
\hline ii & $\begin{array}{l}\text { Some International students are ostracized by the local students with an } \\
\text { assumption that poor English skills mean low intelligence. }\end{array}$ & 6 \\
\hline iii & $\begin{array}{l}\text { The process of the tutorial is slowed by the International student participation } \\
\text { disadvantaging the local students. }\end{array}$ & 4 \\
\hline Q.6. & $\begin{array}{l}\text { What advice would you give to teachers who want to improve their } \\
\text { effectiveness in teaching international students? }\end{array}$ & \\
\hline $\mathrm{i}$ & $\begin{array}{l}\text { Establish group norms at a session in the beginning of the semester. This } \\
\text { should include reference to the diversity of cultures within the class. }\end{array}$ & 7 \\
\hline ii & Be approachable/ accessible. & 6 \\
\hline iii & Establish rapport & 6 \\
\hline iv & Encourage a supportive environment in class. & 5 \\
\hline
\end{tabular}

$*_{n}=5$ Maximum score for a single issue is 15 . Maximum score for a theme is 30 .

Responses that scored below 4 points are excluded. 
TABLE 4

Response to Open Ended Questions - Teaching Difficulties

\begin{tabular}{lll}
\hline & Please list the main difficulties you have teaching or assessing & Content \\
& international students. & analysis \\
\hline a & Language problems & 32 \\
b $\quad$ Participation in class discussions and activities & 27 \\
c $\quad$ Integrating local and international students in groups & 9 \\
d $\quad$ Marking & 7 \\
e $\quad$ Different learning expectations & 7 \\
f $\quad$ Confidence of students & 5 \\
\end{tabular}




\section{TABLE 5}

Response to Open Ended Questions - Teaching Strategies

\begin{tabular}{lll}
\hline & Please list the best strategies you have employed to provide a better & Content \\
& educational experience to international students. & analysis \\
\hline a & Individual attention & 21 \\
b $\quad$ Listening, understanding and empathising & 14 \\
c $\quad$ Encouraging participation and discussion & 9 \\
d $\quad$ Encouraging or requiring mixed cultural groups & 8 \\
e $\quad$ Use international examples & 7 \\
f $\quad$ Using group activities and group dynamics & 7 \\
g $\quad$ Use their cultural experiences & 6 \\
h $\quad$ Use personal and practical experiences/ examples & 6 \\
i & Speak clearly/ paraphrase & 5 \\
\hline
\end{tabular}


TABLE 6

Language Related Focus Group Responses

Use of Language Responses From Focus Groups

Ineffective Language Use

- Heavy accents

- Speaking too fast

- Using colloquialisms

- Terms based on stereotypes

- Use of stereotypes
Effective Language Use

- Try to speak clearer English

- Use a moderate speech speed

- Explain colloquialisms

- Use inclusive language

- Be both tentative and respectful

when describing your perceived

characteristics of another culture/

nation 